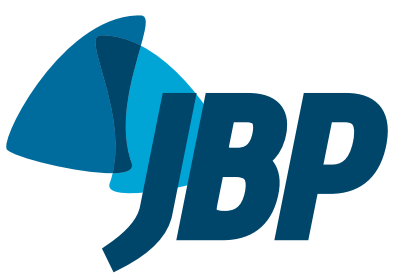

\section{Celebrating World Asthma Day in Brazil: is the glass half full or half empty?}

\author{
Marcia Margaret Menezes Pizzichini1,a, Álvaro Augusto Cruz ${ }^{2,3, b}$
}

Asthma is a chronic respiratory disease that affects 339 million individuals worldwide, of whom approximately 20 million are in Brazil. (1) Since 1998, the Global Initiative for Asthma has globally celebrated "World Asthma Day", which has the objective of raising awareness of the disease and how it affects patients' lives. In Brazil, the Brazilian Thoracic Association has long promoted "National Asthma Day" and "World Asthma Day". This year, "World Asthma Day" will be celebrated on May 7 and will have "STOP for Asthma" as its theme, STOP being an acronym for Symptoms (symptom assessment); Test (asthma control); Observe (and assess); and Proceed (with and adjust treatment). This is a time for reflection, and it seems natural to ask, "What is the asthma scenario like in Brazil today? Is the glass half full or is it half empty?"

For the optimists, among whom we include ourselves, the glass is half full. Not everyone, like us, lived those days when, in order to treat asthma, we only had theophylline, oral corticosteroids, and short-acting $B_{2}$ agonists for use orally or by nebulization. Those were the days when emergency rooms and wards were crowded with asthma patients. It is indisputable that there have been great advances in knowledge about the pathophysiology of asthma in recent decades, and that, consequently, there has been a remarkable increase in the number of asthma control medications available. However, the benefits of these advances in knowledge do not extend to all in need.

Paradoxically, asthma control remains suboptimal worldwide. ${ }^{(2,3)}$ In 2011, a survey involving several countries in Latin America interviewed 2,169 adult patients with asthma or parents of children with asthma; only $9 \%$ of the Brazilian respondents had controlled asthma. ${ }^{(3)}$ With regard to the past 12 months, $27 \%$ of the Brazilian respondents reported having been hospitalized and an additional $47 \%$ reported having received emergency room treatment. ${ }^{(4)}$ More recently, study of data from a previous survey ${ }^{(5)}$ of 12,000 Brazilian adults who agreed to complete the study questionnaire showed that $4.1 \%$ of the respondents had a previous diagnosis of asthma. Of those, $52.1 \%, 36.4 \%$, and $12.3 \%$ had uncontrolled asthma, partially controlled asthma, and controlled asthma, respectively. Only $32.4 \%$ of the respondents reported full adherence to the prescribed treatment regimen. When compared with controls, asthma patients had poorer quality of life and a higher number of hospitalizations in the past 6 months. Work productivity (rates of absenteeism and presenteeism) was lower in asthma patients than in controls. ${ }^{(5)}$
Do these results indicate that the glass is half empty? Yes, as far as asthma control is concerned. Pulmonologists, clinicians, and pediatricians involved in asthma management in Brazil face several challenges that vary in complexity according to local and patient socioeconomic and cultural conditions, patient beliefs and attitudes, the resources available in health care facilities to investigate and confirm the diagnosis of asthma, the level of patient access to the prescribed medications, physician work overload, etc. In addition, asthma is a complex and heterogeneous disease, for which inhaled drug treatment in itself poses a challenge regarding the correct use of inhalers and treatment adherence, as well as regarding the choice of the most appropriate inhaler and the most appropriate dose for a given patient. ${ }^{(6)}$ That said, we should add that the vast majority of asthma patients are found in primary and pediatric care clinics. For this vast majority of asthma patients, treatment is simple, with rapid resolution of symptoms, since asthma is a concordant disease (i.e., the more severe the symptoms are, the more severe is the airway inflammation), which usually responds well to symptom-guided treatment. ${ }^{(7)}$

If most asthma patients have treatment-responsive asthma $^{(7)}$ and can easily control it, then why does asthma control remain suboptimal? In addition to several voluntary and involuntary factors involved in treatment adherence, ${ }^{(6)}$ a plausible possibility is poor physicianpatient communication. ${ }^{(8,9)}$ As in any chronic disease, the physician-patient relationship cannot be just rhetoric; it should be a reality in which the physician sets aside time to establish trust and bond with the patient. Suboptimal asthma control most likely results from the combination of lack of a tailored approach, both biologically and psychosocially, and lack of detailed knowledge about the behavior of patients, with their expectations and fears, as well as from difficulties in choosing the most appropriate inhaler for each patient. $(6,10)$ Poor asthma control rates are red flags calling attention to the need for interventions aimed at developing the skills not only of physicians but also of the entire health care team for understanding the complexity of asthma. Asthma does not have a single diagnostic biomarker, and its treatment requires the use of inhalers. However, in most cases, the disease can be controlled very easily by using medications dispensed free of charge under the Brazilian Popular Pharmacy program.

There are also concrete data showing that the glass is half full. In Brazil, longitudinal trends in asthma health care use have shown that, between 2008 and 2014, 
there was a mean decrease of $43 \%$ in the number of asthma-related hospitalizations among patients aged 1 to 49 years, a finding that is consistent with the provision of medications free of charge via the Brazilian Unified Health Care System as of 2008.(11) These data are encouraging but can be greatly improved. In Finland, ${ }^{(12)}$ a program aimed at increasing asthma diagnosis and control that was implemented 27 years ago resulted in a significant reduction in asthma-related costs despite an increase of almost $300 \%$ in the number of asthma diagnoses in the same period. Costs per patient decreased by $72 \%$. In addition, the proportion of patients with severe asthma exacerbation decreased from $20 \%$ to $2.5 \%$. The success of the program was attributed to the local emphasis, the engagement of all staff involved in asthma management, and the view that asthma is a public health problem whose solution should involve health care professionals and the public through targeted educational campaigns and zero tolerance to underdiagnosis and undertreatment of asthma. ${ }^{(13)}$ It could be argued that Finland is a small, developed country. Several municipal-level experiences in Brazil have shown that the same can successfully be done in our country when there are specialists willing to work in the Brazilian Unified Health Care System to provide referral centers and train primary health care professionals. ${ }^{(14-17)}$

In conclusion, it is time we stopped looking at the glass and rolled up our sleeves. Let us fill up the glass together. We want a Brazil where everyone can breathe!

\section{REFERENCES}

1. The Global Asthma Report 2018. Auckland, New Zealand: Global Asthma Network; 2018.

2. Nathan RA, Thompson PJ, Price D, Fabbri LM, Salvi S, González-Díaz S, et al. Taking Aim at Asthma Around the World: Global Results of the Asthma Insight and Management Survey in the Asia-Pacific Region, Latin America, Europe, Canada, and the United States. J Allergy Clin Immunol Pract. 2015;3(5):734-42.e5. https://doi. org/10.1016/j.jaip.2015.04.013

3. Maspero JF, Jardim JR, Aranda A, Tassinari C P, Gonzalez-Diaz SN, Sansores $\mathrm{RH}$, et al. Insights, attitudes, and perceptions about asthma and its treatment: findings from a multinational survey of patients from Latin America. World Allergy Organ J. 2013;6(1):19. https://doi. org/10.1186/1939-4551-6-19

4. Marchioro J, Gazzotti MR, Nascimento OA, Montealegre F, Fish J, Jardim JR. Level of asthma control and its relationship with medication use in asthma patients in Brazil. J Bras Pneumol. 2014;40(5):487-94 https://doi.org/10.1590/S1806-37132014000500004

5. Cançado JED, Penha M, Gupta S, Li WW, Julian GS, Moreira ES Respira project: Humanistic and economic burden of asthma in Brazil. J Asthma. 2019;56(3):244-251. https://doi.org/10.1080/02770 903.2018.1445267

6. Braido F, Chrystyn H, Baiardini I, Bosnic-Anticevich S, van de Molen T, Dandurand RJ, et al. "Trying, But Failing" - The Role of Inhaler Technique and Mode of Delivery in Respiratory Medication Adherence. J Allergy Clin Immunol Pract. 2016;4(5):823-32. https:// doi.org/10.1016/j.jaip.2016.03.002

7. Haldar P, Pavord ID, Shaw DE, Berry MA, Thomas M, Brightling $\mathrm{CE}$, et al. Cluster analysis and clinical asthma phenotypes. Am J Respir Crit Care Med. 2008;178(3): 218-224. https://doi.org/10.1164/ rccm.200711-17540C

8. Náfrádi L, Nakamoto K, Schulz PJ. Is patient empowerment the key to promote adherence? A systematic review of the relationship between self-efficacy, health locus of control and medication adherence. PLoS One. 2017;12(10):e0186458. https://doi. org/10.1371/journal.pone.0186458

9. Price $D$, Fletcher $M$, van der Molen T. Asthma control and management in 8,000 European patients: the REcognise Asthma and
LInk to Symptoms and Experience (REALISE) survey. NPJ Prim Care Respir Med. 2014;24:14009. https://doi.org/10.1038/npjpcrm.2014.9

10. Global Initiative for Asthma [homepage on the Internet]. Bethesda: Global Initiative for Asthma; [cited 2019 Apr 1]. Global Strategy for Asthma Management and Prevention, 2018. Available from: www. ginasthma.org

11. Comaru T, Pitrez PM, Friedrich FO, Silveira VD, Pinto LA. Free asthma medications reduces hospital admissions in Brazil (Free asthma drugs reduces hospitalizations in Brazil). Respir Med. 2016;121:21 25. https://doi.org/10.1016/j.rmed.2016.10.008

12. Haahtela T, Herse F, Karjalainen J, Klaukka T, Linna M, Leskelä RL, et al. The Finnish experience to save asthma costs by improving care in 1987-2013. J Allergy Clin Immunol. 2017;139(2):408-414.e2. https:// doi.org/10.1016/j.jaci.2016.12.001

13. Burki TK. Asthma control: learning from Finland's success. Lancet Respir Med. 2019;7(3):207-208. https://doi.org/10.1016/S2213 2600(19)30030-X

14. Souza-Machado C, Souza-Machado A, Franco R, Ponte EV, Barreto $\mathrm{ML}$, Rodrigues LC, et al. Rapid reduction in hospitalisations after an intervention to manage severe asthma. Eur Respir J. 2010;35(3):51521. https://doi.org/10.1183/09031936.00101009

15. Fontes MJ, Affonso AG, Calazans GM, de Andrade CR, Lasmar LM Nader CM, Camargos PA, et al. Impact of an asthma management program on hospitalizations and emergency department visits. $J$ Pediatr (Rio J). 2011;87(5):412-8. https://doi.org/10.2223/JPED.2129

16. Martins SM, Salibe-Filho W, Tonioli LP, Pfingesten LE, Braz PD, McDonwell J, et al. Implementation of 'matrix support' (collaborative care) to reduce asthma and COPD referrals and improve primary care management in Brazil: a pilot observational study. NPJ Prim Care Respir Med. 2016;26:16047. https://doi.org/10.1038/ npjpcrm.2016.47

17. Cerci Neto A, Ferreira Filho OF, Bueno T, Talhari MA. Reduction in the number of asthma-related hospital admissions after the implementation of a multidisciplinary asthma control program in the city of Londrina, Brazil. J Bras Pneumol. 2008;34(9):639-45. https:// doi.org/10.1590/S1806-37132008000900002 